\title{
Aproximaciones a una funcionalización constitucional de la teoría del delito
}

\section{Approaches to a constitutional function on theory of crime}

\author{
YVAN MONTOYA VIVANCO*
}

Resumen: Tras presentar los presupuestos del impacto del neoconstitucionalismo en el derecho penal, el presente artículo plantea las posibilidades de reconstruir los contenidos de las categorías de la teoría del delito hacia los principios y derechos fundamentales reconocidos (explícita o implícitamente) en la Constitución.

Palabras clave: neoconstitucionalismo - teoría del delito - principios y derechos fundamentales - constitucionalización del derecho penal dogmática penal

Abstract: After presenting assumptions of neo constitutionalism impact in criminal law, this article raises the possibilities of rebuild contents of categories on crime's theory towards fundamental principles and rights recognized (explicitly or implicitly) in the Constitution.

Key words: neo constitutionalism - theory of crime - fundamental principles and rights - penal law constitutionalization - criminal dogma

CONTENIDO: I. INTRODUCCIÓN.- II. PRESUPUESTOS TEÓRICOS DE UNA FUNCIONALIZACIÓN CONSTITUCIONAL DE LA DOGMÁTICA PENAL.II.1. LA CONSTITUCIÓN EN UNA PERSPECTIVA ABIERTA.- II.2. EL (NEO) CONSTITUCIONALISMO Y EL REPLANTEAMIENTO DEL CONCEPTO DEL DERECHO.- II.3. EL DERECHO PENAL Y LA RUPTURA DEL FORMALISMO JURÍDICO PENAL EN EL CONTEXTO DEL NEOCONSTITUCIONALISMO.- III. LA DOGMÁTICA PENAL FUNCIONAL Y FUNCIONALIZACIÓN CONSTITUCIONAL DE LA TEORÍA DEL DELITO.- III.1. ANTECEDENTES: LA DOGMÁTICA PENAL DE BASE ONTOLÓGICA.- III.2. LA DOGMÁTICA PENAL FUNCIONAL ACTUAL.III.2.1. LA TEORÍA DEL DELITO ORIENTADA A PRINCIPIOS POLÍTICOCRIMINALES EN CLAUS ROXIN.- III.2.2. LA PERSPECTIVA FUNCIONAL DE VIVES ANTÓN Y SUS DISCÍPULOS.- III.3. RECONSTRUCCIÓN DE UNA FUNCIONALIZACIÓN CONSTITUCIONAL DE LAS CATEGORÍAS DE LA TEORÍA DEL DELITO.- III.3.1. TIPICIDAD (ANTIJURIDICIDAD MATERIAL).- III.3.2. LA ANTIJURIDICIDAD FORMAL.- III.3.3.CULPABILIDAD.- IV. CONCLUSIONES. 


\section{INTRODUCCIÓN}

La relación entre el derecho constitucional y el derecho penal -0 , mejor expresado, las relaciones entre los contenidos explícitos e implícitos de la Constitución y el derecho penal- ha estado determinada tradicionalmente por un grupo de principios que operaban como límites a la potestad punitiva del Estado: legalidad, proporcionalidad, lesividad, culpabilidad, entre otros. Todos los principios mencionados han operado, en un primer momento, como límites externos a la potestad punitiva del Estado a la manera de principios político-criminales que orientaban el trabajo del legislador penal. Y en un segundo momento, con el fenómeno del constitucionalismo o neoconstitucionalismo ${ }^{2}$, tales principios han pasado a ser jurídicamente vinculantes al legislador penal por su reconocimiento explícito (legalidad y proporcionalidad) ${ }^{3} \mathrm{O}$ implícito (culpabilidad y lesividad ${ }^{4}$ ) en nuestra Constitución.

En tal sentido, la relación entre los contenidos de la Constitución y del derecho penal, como puede evidenciarse, estuvo dirigida de manera casi exclusiva a los procesos de criminalización y, por ende, al legislador penal (salvo la prohibición de la analogía). La idea central era dotar de normas vinculantes que impidieran, limitaran o racionalizaran el proceso de tipificación de conductas y de adscripción de penas a tales conductas.

Sin embargo, se evidencia progresivamente una dimensión de operatividad práctica de tales principios y derechos fundamentales en el trabajo dogmático-penal y, como consecuencia de ello, en los contenidos de la propia teoría del delito. En efecto, no se trata ahora solo de límites externos a la configuración normativa del derecho penal, sino de principios y normas iusfundamentales que configuran también el aparato teórico sobre el cual se asienta la aplicación ordinaria de la ley penal. Esta comprensión del impacto del neoconstitucionalismo sobre el derecho penal ha tenido un mayor desarrollo histórico en la doctrina penal italiana que en la doctrina penal alemana ${ }^{5}$, la cual ha permanecido mucho más centralizada en el desarrollo sistemático del derecho penal ajeno al desarrollo constitucional.

1 Solo a título de ejemplos los manuales de MuÑOz CONDE, Francisco y Mercedes García ARAN. Derecho penal. Parte general. Séptima edición. Valencia: Tirant lo Blanch, 2007 (caps. IV y V); Berdugo Gómez de LA TORRE, Ignacio y otros. Curso de Derecho Penal. Parte general. Barcelona: Experiencia, 2004 (Lección 3, cap. II); LUZÓN PEÑA, Diego Manuel. Lecciones de Derecho Penal. Parte general. Valencia: Tirant lo Blanch, 2013 (cap. 2). En el Perú, el manual de VILLAVICENCIO TerReros, Felipe. Derecho Penal. Parte general. Lima: Grijley, 2006.

2 Sobre la terminología, ver el acápite 2.1 de este trabajo.

3 Artículos 103, 2.24 d y 200 de la Constitución Política.

4 Sobre el reconocimiento constitucional de estos principios, ver las sentencias de Tribunal Constitucional de fecha 9 de agosto de 2006 (expediente 003-2005) y de fecha 15 de diciembre de 2006 (expediente 0012-2006 PI/TC).

5 Sobre esta constatación desde la perspectiva alemana, ver especialmente TIEDEMANN, Klaus. Constitución y derecho penal. Lima: Palestra, 2003. 
Sin embargo, a pesar de las reflexiones del carácter fundante de la Constitución sobre el derecho penal, la doctrina italiana no ha llevado su experiencia histórica hasta las últimas consecuencias, es decir, no ha culminado su desarrollo hasta involucrar los contenidos constitucionales en la teoría del delito.

La teoría del delito constituye uno de los desarrollos dogmáticos más complejos que ha elaborado una disciplina jurídica. Se trata, en buena cuenta, de una construcción sistemática histórica de las disposiciones y normas penales que ha determinado una estructura de análisis del fenómeno delictivo sobre la base de un sistema de filtros o niveles de juicios de valoración (tipicidad, antijuridicidad y culpabilidad), cada uno con diverso contenido. Este sistema de filtros tiene como pretensión esencial brindar al juez herramientas de interpretación jurídica para poder atribuir un suceso concreto a un injusto penal predeterminado y, de esta manera, poder reprochar penalmente a una persona concreta tal injusto penal cometido ${ }^{6}$.

Pues bien, el propósito de este trabajo es, en primer lugar, presentar las bases o presupuestos del impacto del constitucionalismo o neoconstitucionalismo en el derecho penal y, a partir de allí, plantear las posibilidades de reconstruir u ofrecer una funcionalización de los contenidos de las categorías de la teoría del delito hacia los principios y derechos fundamentales reconocidos (explícita o implícitamente) en la Constitución. Pretendemos en buena cuenta seguir contribuyendo en subsanar un vacío advertido por Manuel Atienza en la dogmática penal actual: explicar la subordinación de los elementos descriptivos, explicativos y sistemáticos de la dogmática a los elementos de carácter valorativo.

\section{PRESUPUESTOSTEÓRICOSDEUNAFUNCIONALIZACIÓN CONSTITUCIONAL DE LA DOGMATICA PENAL}

Antes de evaluar las posibilidades de reconstrucción constitucional de una dogmática penal funcional $-\mathrm{y}$ por ende de su desarrollo más complejo, como es la teoría del delito-, es importante dar cuenta de los puntos de partida teóricos que nos permiten la referida reconstrucción.

6 Sobre la importancia de la dogmática jurídico-penal en el contexto de un Estado democrático de derecho, ver GIMBERNAT, Ordeig. “¿Tiene futuro la dogmática jurídico penal?». En Santiago MIR y Mirentxu Corcoy (dirs.). Estudios de Derecho Penal. Madrid: Tecnos, 1990, p. 160.

7 ATIENZA, Manuel. «Constitucionalismo y derecho penal». En Constitución y derecho penal. Madrid: Marcial Pons, 2012, p. 39. 


\section{II.1. La Constitución en una perspectiva abierta}

Como consecuencia de los procesos de constitucionalización y democratización surgidos en Europa occidental ${ }^{8}$ después de la Segunda Guerra Mundial, las constituciones políticas de los Estados han venido adquiriendo progresivamente una cualitativa importancia, entendiéndola como un cuerpo normativo fundacional y vinculante para todos los órganos del Estado?.

Sin embargo, esta naturaleza normativa de la Constitución no puede entenderse como un sistema jurídico cerrado sino como un sistema abierto $^{10}$, esto es, como un sistema cuyas normas iusfundamentales le permiten operar una reinterpretación constante de sí misma, adquiriendo una capacidad expansiva y receptiva de los factores sociales y políticos internos e internacionales ${ }^{11}$. Bajo esta concepción, la cual compartimos, resulta entonces infundado el miedo a un inmovilismo del ordenamiento constitucional y de un divorcio entre sistema jurídico fundamental y realidad social. La práctica de nuestro Tribunal Constitucional en estos aproximadamente doce años de desarrollo de los derechos fundamentales es, sin perjuicio de nuestra discrepancia con no pocas sentencias relativamente recientes, buena prueba de ello ${ }^{12}$.

Pero el proceso de constitucionalización que hemos descrito —esto es, la existencia de Constituciones abiertas ahora con caracteres normativos, altamente garantizadas a través de diversos tribunales y fuertemente impregnadas del reconocimiento de derechos de las personas - ha motivado un intenso proceso de reflexión teórica sobre sus diferentes alcances, lo que ha dado lugar a perspectivas teóricas con rasgos comunes, pero también con relevantes matices que veremos en el acápite siguiente. Estas perspectivas teóricas han

8 Al respecto, ver las Constituciones de Francia 1946, Italia 1948, Alemania 1949 y España, 1978.

9 Sobre el período anterior a la Segunda Guerra Mundial, consultar MUÑOz CONDE, Francisco. Edmund Mezger y el derecho penal de su tiempo. Ob. cit., p. 104. Este autor nos devela el desprecio que muchos penalistas alemanes mostraban hacia la Constitución de la República de Weimar. Tal vez esta tradición, no solo de desconocimiento de la Constitución sino de animadversión hacia ella, explique en parte el retraso que con respecto a Italia o España muestra la dogmática penal alemana acerca de la incidencia de la Carta Fundamental en la política criminal y en la dogmática penal. Sobre este retraso, ver SANTANA VEGA, Dulce María. La protección penal de los bienes jurídicos colectivos. Ob. cit., pp. 31 y 32. TIEDEMAN, Klaus. «La constitucionalización de la materia penal en Alemania». En:

www.unifr/derechopenl/anuario/94, si bien reconoce los problemas de la influencia del derecho constitucional en el derecho penal alemán, atribuye estos problemas a otros factores: falta de tradición en la materia y diversos niveles de abstracción entre los principios constitucionales y los principios penales.

10 LINDE PANIAGUA, Enrique. La constitución abierta. Madrid: Linde, 1991.

11 lbíd., p. 11, fundamenta el carácter abierto en diversas disposiciones de la Constitución española de 1978. Así, la cláusula de remisión a la ley, la cláusula de transformación del artículo 9.2, la cláusula de apertura de los tratados, la cláusula de interpretación de los derechos humanos de conformidad con el derecho internacional, entre otros preceptos.

12 Solo a título de ejemplo pueden citarse dos sentencias de nuestro Tribunal Constitucional. Por un lado, la sentencia sobre la legislación antisubversiva (STC de fecha 3 de enero de 2003, expediente 0010-2002 Al/TC), y por otro, la sentencia sobre el reconocimiento del nuevo derecho fundamental a la verdad (STC de fecha 18 de marzo de 2004, expediente 2488-2002 HC/TC). Con relación a la Constitución española, ver igualmente el trabajo de Díaz REVORIO, Francisco. La Constitución como orden abierto. Ob. cit., p. 208. 
conllevado diferentes términos o nomenclaturas: «constitucionalismo a secas», «neoconstitucionalismo», «constitucionalismo de los derechos», «positivismo inclusivo», «constitucionalismo garantista», etc., pero tal vez el más extendido sea el de neoconstitucionalismo. Como señala María Ángeles Ahumada «se trata de un término [neoconstitucionalismo] acuñado para introducir y plantear en el terreno de la filosofía jurídica una discusión a propósito de los desafíos que diversos aspectos del funcionamiento de los sistemas constitucionales actuales lanzan a la teoría del derecho tradicional» ${ }^{13}$.

Desde este nivel de análisis, dos son los temas principales que determinan las diferencias entre los filósofos del derecho ${ }^{14}$ : el primero es el replanteamiento del concepto de derecho, planteado por la forma de entender la relación entre el derecho y la moral, y el segundo es un tema de carácter metodológico/práctico, es decir, el procedimiento para la determinación y aplicación del derecho.

\section{II.2. El (neo)constitucionalismo y el replanteamiento del concepto del derecho}

En el ámbito de la filosofía del derecho, el fenómeno que hemos descrito anteriormente de constitucionalización del derecho ha dado lugar a una multiplicidad de reflexiones teóricas contemporáneas sobre la manera de entender el derecho ${ }^{15} \mathrm{y}$, en tal sentido, la relación entre este y la moral. En consecuencia, antes de analizar las reflexiones teóricas actuales, cabe recordar las dos perspectivas teóricas del derecho que, históricamente y de manera sucesiva, estuvieron en vigencia. Nos referimos al iusnaturalismo y al positivismo clásico y, en consecuencia, a la tradicional polémica que sostuvieron sobre la forma de concebir la relación entre el derecho y la moral.

El planteamiento iusnaturalista, en resumen, nos indica que por encima del derecho positivo existe un derecho natural o justo, esto es, principios universales e inmutables que se derivan de la propia naturaleza ${ }^{16}$. En ese sentido, si el derecho positivo - esto es, el ordenamiento establecido por el Estado- no respeta el derecho natural, no resulta válido.

13 AHUmADA, María Ángeles. «Neconstitucionalismo y constitucionalismo (a propósito de Constitucionalización y Neoconstitucionalismo de Paolo Comanducci)». En Positivismo jurídico y neoconstitucionalismo. Madrid: Fundación Coloquio Jurídico Europeo, 2009, p. 123.

14 Hacen referencia a las diversas perspectivas del neo constitucionalismo FERRAJOLI (aunque este prefiere usar otra nomenclatura). También MORESo, José Juan. La Constitución: modelo para armar. Madrid: Marcial Pons, 2009, p. 223 y ss.

15 Sobre esta amplia gama de posiciones nos remitimos a los textos de AHUMADA, María Ángeles. Ob. cit., pp. 130 y ss., ATIENZA, Manuel. «Sobre Ferrajoli y la superación del positivismo jurídico». En La teoría del derecho en el paradigma constitucional. Madrid: Fundación Coloquio Jurídico Europeo, pp. 133 y ss.

16 Una versión didáctica sobre las características del iusnaturalismo en PECES BARBA, Gregorio; FERnÁndeZ, Eusebio; De Asís, Rafael. Curso de teoría del derecho. Madrid: Marcial Pons, 2000, pp. 296- 306.

APROXIMACIONES

A UNA

FUNCIONALIZACIÓN

CONSTITUCIONAL

DE LA TEORÍA DEL

DELITO

APPROACHES TO A CONSTITUTIONAL

FUNCTION ON

THEORY OF CRIME 
Se evidencia entonces una relación necesaria entre la moral y el derecho. Esto significa que la validez del derecho, bajo esta concepción, depende necesariamente de su adecuación a un determinado código moral.

Esta tesis ha sido criticada duramente, sobre todo en razón de la indeterminación de lo que se entiende por derecho natural, así como por la ausencia de fuerza coactiva en sus postulados ${ }^{17}$.

La tesis positivista parte de postulados distintos del anterior. Según sus postulados, el concepto o validez del derecho no depende de criterios morales o valorativos ${ }^{18}$ sino descriptivos, esto es, del procedimiento previsto en el ordenamiento estatal para su producción. Precisamente una de las críticas más importantes a esta concepción es la ausencia de criterios sustanciales para evaluar la validez de las normas ${ }^{19}$.

Esta concepción del derecho plantea una relación contingente con la moral ${ }^{20}$. En efecto, para los positivistas es deseable que el derecho sea justo, sin embargo consideran que este carácter no es necesario para su valide $z^{21}$.

Ahora bien, teniendo en cuenta el contexto anterior, veamos cómo se pueden clasificar las reflexiones teóricas sobre el concepto de derecho en el contexto del fenómeno de constitucionalización. Siguiendo a Manuel Gedisa Atienza ${ }^{22}$, estas posiciones pueden agruparse en alguna de las siguientes tres perspectivas teóricas:

- Perspectiva positivista clásica: se trata de aquellos que consideran que el fenómeno de la constitucionalización del derecho no conlleva un nuevo paradigma conceptual, es decir, una nueva teoría del derecho. Según esta perspectiva, la identificación del derecho válido «sería sustancialmente la misma que en épocas pasadas», esto es, coherente con el positivismo clásico. En ese sentido, se sigue postulando la relación contingente (mas no necesaria) entre el derecho y la moral, correspondiendo al primero solo las fuentes jurídicas.

- Perspectiva neopositivista del derecho: de acuerdo con esta perspectiva, los cambios operados por el constitucionalismo moderno obligan a plantear un cierto cambio de paradigma jurídico, pero dentro de los parámetros generales esbozados

17 Ibíd., pp. 301-306.

18 HART, H.L.A. El concepto de derecho (traducción del título original The concept of law, Oxford, 1961). Buenos Aires: Abeledo Perrot, 1998, pp. 229 y ss.

19 Con respecto a la críticas dirigidas al positivismo ver DwORKIN, Ronald. El imperio de la justicia. Barcelona: Gedisa, 1988.

20 Gonzales Amuchastegul, Jesús. Autonomía, dignidad y ciudadanía. Valencia: Tirant lo Blanch, 2004, p. 30.

21 lbíd., p. 30.

22 ATIENZA, Manuel. «Constitucionalismo y derecho penal». En Constitución y derecho penal (Mirentxu CorcoY, dir.). Madrid: Marcial Pons, 2012, pp. 21 y 22. 
por el positivismo ${ }^{23}$. Se trata de la posición especial del profesor Ferrajoli. Según Atienza ${ }^{24}$, el aspecto más importante que aleja a Ferrajoli del positivismo clásico puede apreciarse cuando sostiene que, para que una norma infraconstitucional sea válida, no solo debe ser válida formalmente (en cuanto a su producción) sino que también debe ser coherente con los contenidos sustanciales (las opciones de deber ser) ${ }^{25}$ de las normas iusfundamentales. Pero a pesar de estos reconocimientos, Ferrajoli se sigue afirmando positivista en la medida en que «interpreta que los elementos de esa dualidad tienen un derecho autoritativo», es decir, las dimensiones del derecho derivan de un derecho puesto, o del derecho «que es».

- Perspectivas pospositivistas ${ }^{26}$ (o verdaderamente neoconstitucionalistas): son representantes de esta gama de posturas (las cuales mantienen matices diferentes) los profesores Ronald Dworkin, Robert Alexy, Santiago Nino y, desde nuestro punto de vista, también el profesor Manuel Atienza. En general, se trata de perspectivas que denotan claramente la dualidad interna del derecho ${ }^{27}$. Más allá del tipo de separación entre reglas y principios, esta concepción considera que ambos tipos de normas (incluso las reglas, aunque se aprecia mejor en los principios) contienen una dualidad interna de elementos: un elemento positivo o descriptivo (la Constitución como es) y un elemento ideal o valorativo (la pretensión de corrección del derecho que es). Es evidente, de lo dicho hasta aquí, que las posiciones agrupadas en esta perspectiva reconocen una relación necesaria (al menos conceptual) entre la moral y el derecho, sin que ello signifique una vuelta al iusnaturalismo ${ }^{28}$.

Precisamente los derechos o principios fundamentales son expresión clara e inequívoca de esa relación estrecha entre derecho y moral. En efecto, los derechos o principios fundamentales han sido concebidos como expresión de las exigencias morales que se consideran importantes

23 El mismo FERRAJOLI sostiene que él no es partidario de paleopositvismo entendido como aquel modelo teórico del Derecho en el que "la norma de reconocimiento consistía simplemente en el principio de legalidad acorde a la formula hobbesiana autorictas facie legem. La validez equivalía a la existencia de las normas y la existencia a su vez validez". Al respecto ver Entrevista a Luigi Ferrajoli por Gerardo Pissarello y Ramon Suriano, en: http://www.miguelcarbonell.com/artman/uploads/1/ entrevista_a_luigi.pdf.

24 ATIEnZA, Manuel. «Sobre Ferrajoli y la superación del positivismo jurídico». Ob. cit., p. 148.

25 FeRRAJOLI, Luigi. «La teoría del derecho en los sistema de los saberes jurídicos». En La teoría del derecho en el paradigma del sistema constitucional. Madrid: Fundación Coloquio Jurídico Europeo, 2008, pp. 37 y ss.

26 ATIENZA, Manuel. «Constitucionalismo y derecho penal». Ob. cit., p. 22, aunque he preferido suprimir la nomenclatura de posiciones no positivistas.

27 lbíd., p. 22.

28 IGLESIAS VILA, Marisa. «El positivismo en el Estado constitucional». Ob. cit., p. 78.

APROXIMACIONES

A UNA

FUNCIONALIZACIÓN

CONSTITUCIONAL

DE LA TEORÍA DEL

DELITO

APPROACHES TO A CONSTITUTIONAL

FUNCTION ON

THEORY OF CRIME 
para los seres humanos, para una colectividad o para todo un pueblo ${ }^{29}$. Si bien las exigencias morales no deben entenderse como exigencias absolutas, válidas para todo momento histórico, tampoco deben entenderse como exigencias coyunturales, absolutamente discrecionales o subjetivas ${ }^{30}$. La moralidad aludida no hace referencia a una moral social aprobada $^{31}$ por la mayoría o la minoría de las personas ${ }^{32}$. La moral a la que aludimos es la moral crítica o ideal, esto es, aquella compuesta «por principios morales generales usados en la crítica de instituciones sociales reales, incluida la moralidad positiva ${ }^{33}$.

Todo este recorrido por la relación entre derecho y moral nos permite sostener que los principios y los derechos fundamentales recogidos explícita o implícitamente en la Constitución están compuestos no solo por una dimensión descriptiva basada en la autoridad, sino por una dimensión axiológica que marca exigencias morales. Ambas dimensiones impregnan o deben impregnar las normas penales en tanto reglas.

Las conclusiones a las que hemos llegado tienen una incidencia relevante sobre la dimensión metodológico-práctica del derecho penal, esto es, sobre la dogmática penal y, finalmente, sobre el procedimiento para la determinación y aplicación de las disposiciones penales.

29 PRIETO SANCHIS, Luis. «Derechos fundamentales, neoconstitucionalismo y ponderación judicial». Ob. cit., p. 31. También concibe los derechos humanos como exigencias morales GonZALES AmUCHASTEGUI, Jesús. Autonomía, dignidad y ciudadanía. Ob. cit., p. 33.

30 Gonzales Amuchastegul, Jesús. Autonomía, dignidad y ciudadanía. Ob. cit., p. 55.

31 Una explicación sintética de la diferencia entre moral positiva y moral crítica la encontramos en GonZALES AmUCHAStegul, Jesús. Autonomía, dignidad y ciudadanía. Ob. cit, p. 33.

32 Es precisamente esa moral positiva la que es criticada con razón por los profesores BERDUGo GómEZ DE LA TORRE, Ignacio y ARROYo ZAPATERo, Luis. Manual de derecho penal. Parte general I. Ob. cit., p. 7.

33 Sobre la objetividad de esta moral, ver esencialmente HABERMAS, Jurgen. Conciencia moral y acción comunicativa. Barcelona: Península, 1996, pp. 57 y ss. También en esa misma línea, ATIENZA, Manuel. "Sobre Ferrajoli y la superación del positivismo jurídico». Ob. cit., p. 138. Según este último autor, Luigi Ferrajoli se sitúa entre los autores que niegan la posibilidad de una construcción objetivable de la dimensión moral del derecho. Eso explica la posición de Ferrajoli cercana con la interpretación y subsunción como procedimientos para determinar y aplicar el derecho. El temor más grave que manifiestan Ferrajoli y aquellos que cuestionan esta vinculación conceptual entre moral y derecho es la pérdida de capacidad crítica al derecho positivo, que solo la ofrecería una separación tajante entre derecho positivo y moral. Plantear el contenido de las normas iusfundamentales como compuestas por dos dimensiones (dimensión autoritativa y dimensión axiológica, entendida como pretensión de corrección del enunciado legal) nos retornaría — dice Ferrajoli- al iusnaturalismo, al identificar la validez (la obligatoriedad) del derecho no de su positividad, sino a partir de su componente moral. En mi concepto, siguiendo a Atienza, tres son los elementos que nos permiten escapar de los riesgos anunciados por Ferrajoli: primero, no se trata de normas parciales o coyunturales sino de una moral crítica, tal como lo hemos expresado; segundo, el contenido axiológico determinado en algún momento determinado no es concluyente: puede cambiar en función de mejores argumentos en el contexto del discurso comunicativo, y tercero, sostener que las normas iusfundamentales contienen una dimensión axiológica ( $y$ en una perspectiva interna supone actuar en consecuencia) no impide tener una perspectiva externa que cuestione el derecho positivo, incluso las normas constitucionales. 


\section{II.3. El derecho penal y la ruptura del formalismo jurídico penal en el contexto del neoconstitucionalismo}

Si asumimos la conclusión a la que hemos llegado en el acápite anterior, no es difícil deducir las implicancias que el neoconstitucionalismo, como teoría del derecho, tiene sobre el derecho penal y sobre el marco teórico de aplicación de las disposiciones penales, es decir, la dogmática penal.

2.3.1. El derecho penal ya no puede definirse como tradicionalmente se la entendía, esto es, como el conjunto de normas (concebidas solo como reglas) jurídicas que asocian al delito, como presupuesto, penas o medidas de seguridad, como consecuencia jurídica ${ }^{34}$ y 35 , sino como un conjunto de «normas [entendidas como reglas], valoraciones y principios jurídicos que desvaloran y prohíben la comisión de delitos y asocian a estos como presupuestos, penas o medidas de seguridad $\aleph^{36}$.

Como veremos posteriormente, en el control cotidiano de la conformidad de una disposición penal con la Constitución es fundamental apelar a la dimensión valorativa de esta, lo cual solo es deducible de la dimensión axiológica derivada de los principios y derechos que se reconocen en ella y en los instrumentos internacionales de derechos humanos ${ }^{37}$. Esta dimensión valorativa en las normas contenidas en las reglas del derecho penal lleva también a adoptar una posición con relación a la tradicional y no concluida polémica sobre la estructura de la norma penal. Nos referimos al debate sobre si la norma penal contiene solo una dimensión imperativa (función de motivación) o también incluye una dimensión valorativa (expresión de un juicio de valor sobre el suceso realizado).

Mientras algunos penalistas han concentrado su perspectiva dogmática sobre la base de una norma penal concebida únicamente como norma imperativa ${ }^{38}$, otros la han concebido en su dimensión esencialmente

34 ATIEnZA, Manuel. "Constitucionalismo y derecho penal». Ob. cit., p. 27, cita como superada la definición que hace Mir Puig en su Tratado de derecho penal de 1997.

35 Sin embargo, es preciso señalar que, a pesar de la tradicional definición formal (del concepto de derecho penal) esgrimida por los penalistas en su conjunto, esta siempre ha sido flexibilizada a través de la introducción del denominado "concepto material del delito", entendiendo por tal generalmente aquella conducta que de manera culpable lesiona o pone en peligro bienes jurídicos o es socialmente dañina. Según LAMPE, Ernst Joachim. La dogmática jurídico-penal: entre la ontología social y el funcionalismo. Traducción a cargo de Carlos Gómez Jara, Guillermo Orce y Miguel Polaino Orts. Lima: Grijley, 2003, pp. 34 y 35, esta concepción de «principio material de injusto» tiene como una de sus funciones el rol de un «topos de interpretación» a efectos de medir los diferentes tipos penales de la parte especial y evaluar si desborda la sustancialidad del ideal material de injusto punible. El mismo autor relaciona ese "topos interpretativo" con el rol que puede cumplir con el principio constitucional de proporcionalidad, pero no le otorga alcance suficiente dado que lo interpreta como proporcionalidad en sentido estricto y no como constitucionalmente ahora se comprende.

36 MIR PUIG. Ob. cit.

37 DonINI, Massimo. El derecho penal entre los desafíos de la modernidad. Lima: ARA editores, p. 345.

38 Representantes de la perspectiva monista son, según RoxIN, Claus. Derecho penal. Parte general. Tomo I. Madrid: Civitas, 1997, p. 321, tanto Zielinsky como Horn. En América Latina resulta emblemático SANCINETTI, Marcelo. Fundamentación subjetiva del ilícito y desistimiento de la tentativa. Bogotá: Temis, 1995.

\section{APROXIMACIONES \\ A UNA \\ FUNCIONALIZACIÓN \\ CONSTITUCIONAL \\ DE LA TEORÍA DEL \\ DELITO}

APPROACHES TO A CONSTITUTIONAL FUNCTION ON THEORY OF CRIME 
valorativa ${ }^{39}$. Cabe añadir que un tercer grupo reconoce paritariamente las dos dimensiones de la norma penal, lo que exige, en coherencia con los postulados neoconstitucionalistas, disponer de dos ámbitos o momentos de análisis del suceso concreto: un ámbito de juicio de dicho suceso sobre bases axiológicas (posibilidad de afectación del bien jurídico), y otro ámbito de juicio sobre bases prescriptivas o imperativas (comportamiento consciente del significado de la infracción de la norma). En mi consideración, la dimensión axiológica es la que nos determina la adopción de una concepción dual del injusto (material) típico: el desvalor (axiológica) de la acción y el desvalor (axiológica) del resultado ${ }^{40}$.

2.3.2. Una concepción del derecho $-\mathrm{y}$ del derecho penal en particular - como un conjunto de normas que integran las dos dimensiones: la imperativa y especialmente la valorativa, debe conllevar a aceptar pacíficamente el método ponderativo como fórmula previa para determinar, en los casos difíciles pero también en no pocos casos comunes, el alcance concreto de una regla que contiene una norma penal. La concurrencia de principios o derechos fundamentales en la delimitación del alcance de un tipo penal no puede, dado el carácter dúctil de los principios y derechos fundamentales, resolverse a través de un procedimiento de subsunción.

A pesar de lo mencionado, Atienza nuevamente ha advertido la paradoja de algunos penalistas (como el caso del profesor Vives Antón) que conciben la norma penal como norma de valoración (principalmente) pero se oponen sustancialmente a la ponderación como una fase del procedimiento para la determinación concreta de la norma penal en algunos casos. Otros penalistas, que priorizan la dimensión imperativa de la norma penal, no tienen reparos en aceptar este procedimiento (como es el caso de Mir Puig ${ }^{41}$ ).

Uno de los supuestos tradicionales en los cuales el operador judicial, antes de la aplicación concreta de un precepto penal, debe acudir a un procedimiento de ponderación (para determinar el injusto penal aplicable) es el de las causas de exclusión del injusto típico y, dentro ellos, especialmente los supuestos de ejercicio legítimo de un derecho ${ }^{42}$. En este tipo de casos, el proceso de subsunción (y la aplicación del

39 En una primera etapa, el profesor VIVES ANTÓN citado por ATIENZA, Manuel. «Constitucionalismo y derecho penal». Ob. cit., p. 21.

40 De esta postura, MARTínEZ-BuJÁn PÉREZ, Carlos. El contenido de la antijuridicidad. Valencia: Tirant lo Blanch, 2013.

41 MIR PUIG, Santiago. Bases constitucionales del derecho penal. Madrid: lustel, 2011, pp. 94 y ss.

42 Ejemplos que se suscitan con frecuencia en la jurisprudencia penal los encontramos en la aplicación del tipo penal de difamación (artículo 132 del CP) y su relación conflictiva con el derecho al honor (artículo 2.7 de la Constitución) o en el tipo penal de entorpecimiento al funcionamiento de los servicios públicos (artículo $283 \mathrm{CP}$ ) y su relación conflictiva con el derecho a reunirse de manera pacífica (artículo 2.12 la Constitución). 
silogismo clásico) no es suficiente. En estos casos, la ponderación arroja una regla que acota o condiciona la aplicación del supuesto de hecho a casos que cumplan con algunas características no explicitadas en el tipo penal.

Sin embargo la ponderación, como parte del procedimiento de aplicación de normas penales, no solo se evidencia en los supuestos de exclusión del injusto. Efectivamente, este procedimiento se aplica como paso previo o paralelo a la acotación o interpretación del tipo penal mismo, especialmente en casos difíciles o trágicos y en casos que presuponen una materia altamente conflictiva ${ }^{43}$. Así por ejemplo, dentro de los casos trágicos mencionados, pueden citarse los casos de homicidio consentido o de lesiones consentidas. Estos casos no están regulados de manera axiológicamente explícita en el Código Penal peruano y su solución presupone, aunque sea de manera implícita, un proceso ponderativo entre diversos derechos o principios en conflicto que permita delimitar el alcance de los tipos penales ordinarios. Atienza denomina a este tipo de casos como «supuestos de laguna normativa o de laguna axiológica» ${ }^{44}$. Efectivamente, los ejemplos citados serían en realidad casos de laguna axiológica ${ }^{45}$, esto es, supuestos en los que existe formalmente una regla que regula una determinada situación pero, por la particularidad de dicha situación, la regula inadecuadamente.

Pero en mi concepto existen otros supuestos en los que, sin ser casos trágicos o difíciles, el procedimiento ponderativo resulta necesario para determinar el concreto alcance del tipo penal. Nos referimos a uno de los juicios más importantes que la doctrina penal viene utilizando para la acotación de los tipos penales: el criterio de exclusión de imputación objetiva (de conductas) que denominamos «riesgo permitido». Efectivamente, autores como Paredes Castañón ${ }^{46}$ o el propio Roxin consideran que el criterio final, más allá de las determinaciones que se efectúen en los ámbitos administrativo o gubernamental para determinar el umbral de lo permitido o prohibido del riesgo, lo ofrece el procedimiento ponderativo a cargo del operador judicial.

43 Reconocen este procedimiento ponderativo, entre otros, MIR PUIG. Santiago. «El principio de proporcionalidad como fundamento constitucional de los límites materiales del derecho penal». En Silvia Fernández Bautista (coord.). Constitución y principios del derecho penal. Valencia: Tirant lo Blanch, 2010, pp. 73 y 77 y SÁNCHEZ OSTIZ, Pablo. Fundamentos de política criminal. Madrid: Marcial Pons, 2012, p. 84. Particularmente este último autor señala que política criminal también hace el juez al momento de emitir una sentencia e imponer una condena a un sujeto por hecho realizado. En ese sentido, propone una serie de subprincipios específicos tradicionalmente usados por los órganos judiciales (principio de culpabilidad, principio de prohibición de desproporción, etcétera) y que son una especie de reglas especiales que se derivan de ponderaciones de principios generales.

44 ATIENZA, Manuel. «Constitucionalismo y derecho penal». Ob. cit., p. 35.

45 En el derecho penal está prohibida la analogía in malam parte (artículo del Código Penal).

46 PAREDES CASTAÑón, José Manuel. El riesgo permitido en derecho penal. Madrid: Civitas, 1997, pp. 487 y ss.

APROXIMACIONES

A UNA

FUNCIONALIZACIÓN

CONSTITUCIONAL

DE LA TEORÍA DEL

DELITO

APPROACHES TO A CONSTITUTIONAL FUNCTION ON THEORY OF CRIME 
Es importante señalar que el criterio ponderativo no excluye el momento de subsunción. Como explica Atienza ${ }^{47}$, la ponderación es un procedimiento complejo que consta de dos fases: por la primera, en la cual no se cuenta con una regla (o mejor dicho no se cuenta con una regla suficiente o laguna axiológica), el operador apela a los principios concurrentes al caso a efectos de determinar o precisar la regla de contenido insuficiente o la laguna axiológica, y, por la segunda, una vez precisada la regla o completada la laguna axiológica, se procede a la subsunción al caso ${ }^{48}$.

Evidentemente la reticencia a este procedimiento por muchos penalistas y filósofos del derecho es la arbitrariedad o decisionismo al que puede llevar este procedimiento. Sin embargo, en un contexto inevitable de razonamiento práctico como el que nos ocupa ${ }^{49}$, el objetivo es atender a la «plausibilidad de las decisiones judiciales». Una plausibilidad concebida como «exigencia de racionalidad de lo que se propone» ${ }^{50}$. Pues bien, la razonabilidad del procedimiento ponderativo está bastante desarrollada, especialmente por los criterios sistematizados por Alexy (idoneidad, necesidad y proporcionalidad en estricto) ${ }^{51}$ o Bernal Pulido ${ }^{52}$ desde la teoría del derecho, y especialmente concretizados en materia penal por Lopera Meza ${ }^{53}$ o el propio Mir Puig ${ }^{54}$.

2.3.3. El neoconstitucionalismo también ha consolidado la ruptura metodológica, ya evidenciada con anterioridad ${ }^{55}$, con el formalismo

47 AtienZA, Manuel. «Constitucionalismo y derecho penal». En ob. cit., pp. 34 y 35.

48 Señala al respecto SÁNCHEZ OSTIZ, Pablo. Fundamentos de política criminal. Madrid: Marcial Pons, 2012, p. 60, que los principios son enunciados normativos con pretensiones de validez y aplicación caracterizados por ser origen de otras decisiones jurídicas a las que dan sentido, pero también por estar dotados de elevado grado de abstracción, lo que los hace inoperantes para la aplicación directa por subsunción en ellos, pero que tal aplicación se efectúa a través de reglas a las cuales se llega solo después de operaciones de valoración, ponderación y decisión. Es importante resaltar lo mencionado por el mismo autor en el sentido de que estas soluciones (reglas), si bien se aplican a un número amplio de casos que comparten características semejantes, tienen naturaleza mudable según el contexto ponderativo y la especialidad del caso que plantea una solución.

49 lbíd., p. 29 y 30, con explicaciones sobre los diferentes objetos del saber teórico y del saber práctico.

50 lbíd., p. 30

51 ALEXY, Robert. Teoría de los derechos fundamentales. Madrid: Centro de Estudios Políticos y Constitucionales, 2001. Últimamente el mismo ALEXY en: Epílogo a la teoría de los derechos fundamentales. Madrid: Centro de Estudios, 2004, pp. 32 y ss.

52 Bernal PULIDO, Carlos. El principio de proporcionalidad y los derechos fundamentales. Madrid: Centro de Estudios Políticos y Constitucionales, 2003, pp. 489 y ss.

53 LOPERA MESA, Gloria. «Principio de proporcionalidad y control constitucional de las leyes penales». Jueces para la democracia, 53, 2005.

54 MIR PUIG, Santiago. «El principio de proporcionalidad como fundamento constitucional de los límites materiales del derecho penal». En Constitución y principios del derecho penal. Algunas bases constitucionales. Valencia: Tirant lo Blanch, 2010, pp. 107 y ss., que incluso postula un control más intenso de la ley penal sobre la base del principio de proporcionalidad. Una especial defensa del método ponderativo frente a las críticas de irracionalidad puede encontrarse, según SÁNCHEZ OSTIZ, Pablo. Ob. cit., p. 84 en RodRígueZ de SANTIAGo, J.M. La ponderación de bienes e intereses en el derecho administrativo. Madrid: Marcial Pons, 2000.

55 Ortiz de URBInA Gimeno, Íñigo. La excusa del positivismo. La presunta superación del positivismo y el formalismo por la dogmática penal contemporánea. Madrid: Thomson-Civitas, 2007, quien a lo largo de este texto muestra la necesidad de no confundir términos como los de positivismo y formalismo jurídicos, y advierte que la pretendida evolución que supondría el moderno funcionalismo en el derecho penal (ver punto III) respecto de la dogmática anterior (positivista o formalista-jurídica) no es tal. Señala que aquella concepción formalista del derecho caracterizada por la «confianza en 
jurídico o la hermenéutica legalista. La dogmática penal, anclada en el dogma de la ley, reconoce ahora explícitamente que esta (la ley) y su límite interpretativo marcado por el canon del «sentido literal posible» es un referente débil y graduable. Una manifestación de lo mencionado es la función recreativa o político-criminal que, cada vez más, se aprecia en los operadores de justicia penal.

Efectivamente, Lascuraín ${ }^{56}$ señala, recogiendo la jurisprudencia constitucional española más asentada, que el problema de la vinculación del juez a la ley no puede asentarse suficientemente en el tenor literal de la ley como canon para saber cuándo un operador judicial se ha desvinculado de la ley, violando el derecho a la tipicidad de los ciudadanos. Cita en ese sentido una de las últimas sentencias del Tribunal Constitucional español (STC 129/2008) que en virtud a su valor transcribimos en sus fragmentos pertinentes:

No compete, pues, a este Tribunal la determinación de la interpretación última, en cuanto más correcta, de un enunciado penal, ni siquiera desde los parámetros que limitan los valores y principios constitucionales. Y tampoco le compete la demarcación de las interpretaciones posibles de tal enunciado. De un modo mucho más restringido, y desde la perspectiva externa que le es propia como Tribunal no inserto en el proceso penal, nuestra tarea se constriñe a evaluar la sostenibilidad constitucional de la concreta interpretación llevada a cabo por los órganos judiciales. Tal sostenibilidad se refiere, como se señalaba en el fundamento anterior, al respeto a los valores de la seguridad jurídica y de la autoría parlamentaria de la definición de los delitos y las penas, y se traduce en la razonabilidad semántica, metodológica y axiológica de la interpretación judicial de la norma y de la subsunción legal de los hechos a la misma [...] (FJ 3).

Nótese que en esta parte de la sentencia no se hace mención expresa al criterio del «sentido literal posible» sino a la seguridad jurídica y, en

las posibilidades de resolución precisa de los problemas jurídicos mediante procedimientos lógicoformales a partir exclusivamente del texto de la ley y el juego de los conceptos jurídicos» (pp. 33 y 34) solo estuvo vigente (en el plano conceptual, porque ni siquiera la escuela exegética la creía plenamente aplicable) hasta el siglo XIX, en que la confianza en la «ley perfecta» se desvaneció y la atención giró al rol del juez (p. 39). Indica, en ese mismo sentido, que los planteamientos de la dogmática funcionalista o de la dogmática orientada a las consecuencias no difieren sustancialmente de la forma de hacer dogmática anteriormente. El denominado «positivismo» como el de Binding ya incluía, en su elaboración dogmática, consideraciones extrajurídicas y político-criminales. Concluye entonces que la dogmática funcional moderna (como la de Roxin) solo ha superado métodos como el de la escuela causalista o la finalista, pero no frente al positivismo tal como ha venido trabajando desde mediados del siglo XIX. En mi consideración, si bien es cierto que el positivismo clásico ya trabajaba con criterios de interpretación teleológico-funcionales y no desconocía dimensiones valorativas en el trabajo dogmático, los aspectos cualitativamente diferentes de la dogmática funcional actual (no el funcionalismo sistémico del profesor Jakobs, sobre el cual nos detendremos en el acápite III) radican a mi juicio en el carácter vinculante de la carga valorativa contenida en los derechos y principios constitucionales, la pluralidad de fuentes normativas no basadas exclusivamente en la ley y el procedimiento ponderativo no infrecuentemente utilizado en el ejercicio dogmático actual.

56 LASCURAIN SÁNCHEZ, Juan Antonio. Ob. cit., pp. 103-106. 
tal sentido, a la «razonabilidad semántica», axiológica y metodológica ${ }^{57}$ del proceso de determinación de un tipo penal y de la subsunción del hecho a tal proceso. También hace referencia al respeto a la autoría parlamentaria en la potestad de definir delitos. Pues bien, todo ello nos lleva a sostener que el proceso de elaboración dogmática y, finalmente, de interpretación de las disposiciones penales no tiene un límite exacto o nítido sino graduable. Este límite solo se superará (y por lo tanto la actividad judicial resultará inaceptable constitucionalmente) cuando finalmente el tipo penal utilizado para la subsunción de un hecho concreto no resulte razonablemente comprensivo de este último ${ }^{58}$, y ello a la luz de lo previsible semántica, metodológica y axiológicamente ${ }^{59}$.

Esta textura graduable del límite del procedimiento de interpretación ofrece al operador jurídico la plataforma para que, dentro del marco señalado, pueda apelar a la elaboración de una dogmática funcional y permitir al operador judicial una aplicación funcional y recreativa del derecho.

\section{La dogmática penal funcional y funcionalización constitucional de la teoría del delito}

\section{III.1. Antecedentes: la dogmática penal de base ontológica}

La dogmática penal era concebida por Gimbernat como aquella disciplina «que tiene por objeto el conocimiento de las normas jurídicopenales» y la colocación de «los distintos conceptos logrados en un sistema científico lógicamente irreprochable» ${ }^{60}$. Evidentemente, por norma jurídica se entendía preponderantemente aquel enunciado de carácter prescriptivo contenido en disposiciones de carácter legal (la ley) ${ }^{61}$. En esta perspectiva, la dogmática penal solo cumpliría una función limitadamente garantista. En efecto, bajo esta dimensión positivista legalista, la dogmática penal solo cumplía una función de ordenación sistemática de los conceptos penales y permitía hacer previsibles las decisiones jurisdiccionales. Evidentemente esto aportaba seguridad

57 Un desarrollo amplio sobre este nuevo canon de control del proceso de tipicidad basado en la razonabilidad semántica, axiológica y metodológica puede verse tanto en LASCURAIN SÁNCHEZ, Juan Antonio. Ob. cit., pp. 109-113 y en ALCACER GIRAO, Rafael. Ob. cit., pp. 49-66.

58 LASCURAIN SÁNCHEZ, Juan Antonio. Ob. cit., p. 103. En palabras de SILVA SÁNCHEZ, Jesús María. «Sobre la interpretación teleológica del derecho penal». En ob. cit., p. 393, «lo determinante es, pues, que a la vista del texto y de su contexto (al que pertenece de modo muy significativo el sistema dogmático) la resolución judicial aparezca como una consecuencia, empíricamente previsible, metodológicamente defendible y axiológicamente razonable, del enunciado emitido por el legislador».

59 Nuestro Tribunal Constitucional no ha establecido aún de manera clara, tal como lo ha hecho el Tribunal español, el canon de tipicidad expuesto anteriormente. En la sentencia de fecha 23 de noviembre de 2004 (expediente 2758/2004 HC/TC), el Tribunal reitera el criterio del «tenor literal posible», pero añade también el límite de la interpretación manifiestamente extravagante o irracional «incompatible con el ordenamiento constitucional y su sistema material de valores».

60 Gimbernat Ordeig, Enrique. Concepto y método de la ciencia del derecho penal. Primera reimpresión. Madrid: Tecnos, 2009, pp. 13 y 102.

61 lbíd. 36. 
jurídica, pero a ese nivel de comprensión, el dogmático penal podría hacer previsible también pretensiones autoritarias y expansionistas del legislador penal sin ninguna capacidad crítica $^{62}$.

Los grandes sistemas de la teoría del delito han ofrecido históricamente, dentro del marco del positivismo jurídico (entendido como el dogma de la ley), criterios extrajurídicos de concreción del alcance de lo prohibido del precepto legal en el caso del sistema clásico de la teoría del delito el causalismo, y en el caso del finalismo, las estructuras lógico-objetivas o estructuras ontológicas ${ }^{63}$. A través de estos criterios se pretendía dar sentido, acotar o seleccionar el alcance del sentido de lo prohibido por los preceptos penales. En el caso de las teorías causalistas, se pretendió equiparar el método de determinación de la conducta prohibida y la reprochabilidad de la culpabilidad al método de las ciencias naturales. Algunos $^{64}$ han recordado los aportes del causalismo a una dogmática penal garantista ${ }^{65}$, sin embargo, rápidamente se advirtieron los límites o insuficiencias de este método para servir, aunque sea mínimamente, de criterio de selectividad de conductas relevantes para el tipo penal. La amplitud de la teoría (teoría de la equivalencia de las condiciones), la amplitud del método utilizado (la conditio sine qua non), así como la ineptitud total de estas para explicar modalidades delictivas como los delitos omisivos o los delitos de culpa inconsciente ${ }^{66}$, determinaron su superación.

En el segundocaso — eldela teoría finalista—, se afirmóque determinadas estructuras lógico-objetivas o estructuras ontológicas determinaban el contenido de diversos conceptos dogmáticos de la teoría del delito. Estas estructuras estaban constituidas por la acción final (en el injusto típico)

62 Sin embargo, a pesar de esa perspectiva restringida a la ley positiva, desde hace un buen tiempo los penalistas han operado con criterios de interpretación teleológica y, en especial, con una interpretación orientada al bien jurídico. Esta fórmula ha servido para proyectar, bajo la cobertura de un criterio interpretativo, un sentido de la norma o del alcance de lo prohibido más allá de la comprensión normal del precepto legal. Es evidente que a través de dicha interpretación se abre la posibilidad de otorgar cabida a criterios axiológicos o valorativos. Sin embargo, estos criterios no han tenido tal carácter cuando el bien jurídico de referencia teleológica ha sido construido de manera inmanente. En estos casos, en realidad se ha utilizado el criterio sistemático de interpretación. En cambio, en los casos en que el concepto del bien jurídico de referencia se ha construido de manera trascedente, este, si bien ha tenido una carga axiológica crítica, ha evidenciado un alcance limitado solo al proceso interpretativo.

63 Sobre el limitado aporte del causalismo y el finalismo a la dogmática penal como instrumento de racionalización y resistencia a la potestad punitiva del Estado, ver SILVA SÁNCHEZ, Jesús María. Aproximaciones al derecho penal contemporáneo. Barcelona: Bosch, 1992, pp. 135 y ss. También ERNST Joachim. La dogmática jurídico-penal: entre la ontología social y el funcionalismo. Ob. cit., pp. 59 y ss., el cual refiere la irrelevancia del causalismo avalorado optando por un, denominado por él, «causalismo funcional». Finalmente concluyente en la perspectiva poco rendidora de estas posturas teóricas, específicamente desde las garantías de libertad.

64 BARRERA Jorge y Mario PEREIRA GARMENDIA. Teoría del delito y praxis penal. Aporte del normativismo. Montevideo: Editorial B de F, pp. 5 y ss.

65 lbíd., señalan que a través del causalismo «se tendieron puentes a la consideración de la realidad empírica no jurídica».

66 Mir PuIG, Santiago. Derecho penal. Parte general. Barcelona: Repetor, 2006, pp. 238 y ss.

APROXIMACIONES A UNA

FUNCIONALIZACIÓN

CONSTITUCIONAL

DE LA TEORÍA DEL DELITO

APPROACHES TO A CONSTITUTIONAL FUNCTION ON THEORY OF CRIME 
y por la posibilidad de actuar de otra manera (culpabilidad) ${ }^{67}$. En España ha sido Mir Puig ${ }^{68}$ quien ha dirigido cuestionamientos al finalismo en relación con su escaso o nulo rendimiento, con la posibilidad de limitar o racionalizar la potestad punitiva expresada en la decisión judicial ${ }^{69}$. Señala el referido autor que tales criterios ontológicos del finalismo no son útiles a la hora de determinar, porque las conductas son pasibles de tipificarse de delictivas, ni sirven para determinar el quantum de la pena. En los dos casos, causalismo y finalismo, se pretendió racionalizar el proceso de acotación de la imputación de conductas y de responsabilidad penal a partir de categorías del ser (la causalidad o las estructuras lógicoobjetivas).

Entre estos dos sistemas se ubica el sistema neokantiano, el cual resulta de especial interés dado que plantea los primeros pasos de cara a una construcción dogmática asentada en criterios valorativos. Efectivamente, es en esta etapa donde no solo se descubren elementos subjetivos especiales ya en el tipo penal, sino que metodológicamente se desarrolla el criterio de interpretación teleológica de los tipos penales ${ }^{70}$. La perspectiva neokantiana estaba encaminada a un desarrollo mayor, sin embargo este proceso se interrumpió ${ }^{71}$ durante el desarrollo del derecho penal del terror nacionalsocialista, ofreciendo finalmente limitados aportes. De hecho, si bien el criterio de la interpretación teleológica orientada al bien jurídico fue una perspectiva importante de cara a introducir dimensiones axiológicas en la interpretación de los tipos, esta solo significó un criterio de determinación del alcance del tipo (mera función hermenéutica), muchas veces con resultados extensivos en la interpretación. De cualquier manera, esta perspectiva teleológica se limitó al tipo penal como primer nivel de la estructura de la teoría del delito.

\section{III.2. La dogmática penal funcional actual}

Como reacción a una dogmática penal asentada sobre bases ontológicas, surgen elaboraciones dogmático-penales orientadas funcionalmente. Dos de ellas resultan las más emblemáticas. En primer lugar, debe resaltarse la figura relevante del profesor Claus Roxin con su emblemático trabajo titulado Política criminal y sistema de derecho penal, publicado por primera vez en el año 1970, y en segundo lugar,

67 Roxin, Claus. Evolución y modernas tendencias de la teoría del delito en Alemania. México D.F.: Ubijus, 2009, p. 18.

68 MIR PUIG, Santiago. «Límites del normativismo en derecho penal». En Dogmática y criminología. Bogotá: Legis, 2008 (primera reimpresión), pp. 376 y ss.

69 Estas críticas han sido recogidas por BARRERA Jorge y Mario PeREIRA GARMENDIA . Ob. cit., pp. 16 y 17.

70 Sobre este aspecto ver MocCIA, Sergio. El derecho penal entre ser y valor. Montevideo: Editorial B de F, 2003, pp. 73 y ss.

$71 \mathrm{La}$ aparición del derecho penal del terror durante el período del nacionalsocialismo y su negación con la aparición exitosa del finalismo apagaron durante varias décadas la evolución de la perspectiva valorativa del neokantismo. Esto fue retomado por Roxin en la década de 1970. 
hacerse mención a la reconstrucción dogmático-penal concebida desde un esquema funcionalista sistémico ${ }^{72}$ elaborada por el profesor de Bonn Gunter Jakobs. En nuestra consideración, a diferencia de la perspectiva funcionalista sistémica que resulta incompatible con una concepción neoconstitucional del derecho, solo la perspectiva roxiniana nos ofrece las bases para seguir desarrollando una sistemática (teoría del delito) del derecho penal funcionalizada a los principios y derechos iusfundamentales.

Este texto no resulta el espacio adecuado para explicar ampliamente las razones que nos permiten descartar la opción funcionalista sistémica, sin embargo, resumidamente puede señalarse que esto ocurre sobre todo por el carácter autorreferencial del sistema del derecho penal o la dogmática penal que plantea esta tesis. En efecto, Jakobs separa tajantemente los espacios de la política criminal y de la dogmática jurídico penal ${ }^{73}$ :

La decisión sobre el alcance de los procesos de criminalización sería una tarea puramente política, no jurídico penal ${ }^{74}$.

Si la sociedad realmente se desliza hacia [...] un exceso de criminalización innecesario [...] solo puede determinarse en un plano político, pero no al nivel de la ciencia del derecho penal ${ }^{75}$.

Mussig, uno de los discípulos más cercanos de Jakobs, refuerza estas ideas cuando afirma que las cuestiones de legitimidad material de las normas penales desbordarían el cauce formal (y positivista) de la prevención general positiva y remitirían al análisis de los criterios de identidad de una determinada sociedad ${ }^{76}$. Se concluye entonces que, según esta perspectiva, el derecho se encuentra desligado de la ética, la moral, la política, y que estas expresiones solo irritarían o solo sería ruido que no influye directamente en la comunicación jurídica ${ }^{77}$.

72 Desde la perspectiva de FEIJOO, Bernardo. «La normativización del derecho penal. ¿Hacia una teoría sistémica o hacía una teoría intersubjetiva de la comunicación?». En Teoría de sistemas y derecho penal (coordinador: Carlos Gómez Jara). Bogotá: Universidad de Externado, 2007, p. 477, solo resultaría calificable de funcionalista la dogmática elaborada por el profesor Jakobs, dado que es la única que se comprende en una estructura funcional-sistémica. La dogmática roxinana es calificada por Feijoo como sistema teleológico. Esta opinión es compartida por Amelung. El propio Roxin, en cambio, denomina a su perspectiva como funcionalista. En mi opinión, no veo un inconveniente en denominar a la elaboración dogmática de Roxin como funcionalista, dado que se trata de todo un sistema orientado teleológica o funcionalmente hacia valores y no solo de un mero criterio de interpretación teleológica del tipo penal a partir del bien jurídico.

73 JAKOBS, Gunter. Sociedad norma y persona en una teoría de un derecho penal funcional. Ob. cit., p. 36.

74 JakobS, Günter, ZStW 107 (1995), p. 855, tomado de PEÑARANDA RAmOS, Enrique, Carlos SuÁREZ GONZALES y Manuel CANCIO MELIA. «Consideraciones sobre la teoría de la imputación de Günter Jakobs». Ob. cit., p. 28.

75 JAKOBS, Günter. Sociedad, norma y persona en una teoría de un derecho penal funcional. Madrid: Civitas, 1996, p. 40.

76 Peñaranda Ramos, Enrique, Carlos SuÁRez Gonzales y Manuel Cancio Melia. «Consideraciones sobre la teoría de la imputación de Günter Jakobs». Ob. cit., p. 28.

77 Tomando expresiones de Niklas Luhmann, FEIJOO, Bernardo. «La normativización del derecho penal». Ob. cit., p. 488. 
El neoconstitucionalismo, como hemos señalado en el segundo acápite, determina una identificación del derecho no solo en una dimensión positiva o descriptiva, sino también axiológica o valorativa fuertemente impregnada por aquellos contenidos dúctiles que se incorporan inherentemente en los principios y derechos iusfundamentales. Como advierte Feijoo, «la teoría de los sistemas sociales autopoiéticos plantea un serio inconveniente [...]: es una teoría insuficiente para abordar todas las cuestiones esenciales de la ciencia moderna del derecho penal», especialmente y sobre todo, el aspecto relacionado con la legitimidad del derecho penal y la legitimidad de los contenidos de la dogmática penal ${ }^{78}$ ».

\section{III.2.1. La teoría del delito orientada a principios político-criminales en Claus Roxin}

El profesor Claus Roxin, sin alterar la sistémica del finalismo pero rechazando toda base ontológica, replantea el contenido de cada uno de los niveles tradicionales de la teoría del delito (tipicidad, antijuridicidad y culpabilidad) sobre la base de su orientación a determinados principios político-criminales. En otras palabras, trata de introducir en las categorías tradicionales de la teoría del delito las decisiones valorativas de naturaleza política criminal, valores que de manera consistente se han ido perfilando desde la ilustración hasta las formas de Estado moderno. Sin embargo, Roxin no efectuó un anclaje de tales valores o principios político criminales en el marco de una Constitución vinculante. Veamos resumidamente la perspectiva original del profesor Roxin:

- La tipicidad, primera categoría de la teoría del delito, está determinada por las exigencias del principio nullum crimen, esto es, por las exigencias del principio de legalidad y de seguridad jurídica ${ }^{79}$.

Por otro lado, Roxin también nos evidencia una importante vinculación material entre el mandato de determinación (taxatividad) y el contenido subjetivo del tipo. Nos referimos a la capacidad de los individuos de reaccionar frente a la norma (en su dimensión imperativa) y, en ese sentido, a la exigencia de alguna de las dos dimensiones del tipo de injusto: el dolo o la infracción del deber subjetivo de cuidado, en el caso de los delitos imprudentes.

- La antijuridicidad, segundo nivel sistemático de la teoría del delito, está orientada, según Roxin, por la función de dar solución a los conflictos sociales que resultan de la colisión de intereses de los individuos o de la sociedad ${ }^{80}$. Específicamente, las causas de

78 FEIJOO, Bernardo. Ob. cit., p. 475.

79 Roxin, Claus. Kriminalpolitik und. Strafrechtssystem. Berlín: Gruyter, 1973, p. 16.

80 Roxin, Claus. Ibíd., Pujan, pp. 24 y ss. Aunque Roxin se refiere con mayor propiedad a las causas de justificación más a la categoría de la antijuridicidad. 
justificación (legítima defensa, estado de necesidad justificante, etc.) constituyen criterios de autorización de intervención sobre bienes jurídicos, ofreciendo formas de solventar el referido conflicto de intereses en juego.

La dificultad de encontrar un criterio positivo que oriente la funcionalidad de la categoría de la antijuridicidad radicaría, según Roxin, en la variedad de fundamentos que parece informar las distintas causas de justificación ${ }^{81}$, es decir, no es constatable un único fundamento valorativo para las diversas causas de justificación.

- Con relación a la categoría de la culpabilidad (denominada por Roxin responsabilidad), esta se funcionaliza ${ }^{82}$ sobre la base de su rol frente a los fines de la pena (y no del derecho penal en su conjunto) $^{83}$. En realidad la culpabilidad cumple la función de poner un límite a los criterios de necesidad de pena basados en la prevención (general y especial) de delitos. Y esta culpabilidad, si bien no se asienta en el libre albedrío de las personas dada su indemostrabilidad, sí se basa en criterios de accesibilidad de la persona sobre las posibilidades de un comportamiento orientado a la norma ${ }^{84}$.

\section{III.2.2. La perspectiva funcional de Vives Antón y sus discípulos}

En un trabajo publicado en $1996^{85}$ el profesor Vives Antón realiza un cambio esencial en su perspectiva de razonamiento sistemático del derecho penal (teoría del delito) que difiere de las sistemáticas ontológicas de corte causalista y finalistas. En su lugar, se aproxima más a la perspectiva de un razonamiento sistemático orientado teleológicamente ${ }^{86}$. Esta nueva concepción de los fundamentos del sistema penal parte de la denominada concepción significativa de la acción (o del delito) asentada en las ideas básicas de la filosofía del segundo Wittgenstein, el cual adopta una perspectiva centrada más en la acción y en el lenguaje (entendido como expresión de la cultura y mediadora del significado que porta la realidad) que en el sujeto ${ }^{87}$. De acuerdo con estos postulados, la relevancia jurídico penal de un comportamiento (análisis desde la teoría del delito) es vista desde su práctica misma en tanto aquel es portador de significado. Sin embargo, este significado - del cual es portador la realidad, el comportamiento humano o los propios enunciados legales - es asignado pasando por

81 Roxin, Claus. Kriminalpolitik... Ob. cit., pp. 27 y ss.

82 Roxin, Claus. Ibíd., pp. 33 y ss.

83 De hecho la pena solo es atribuible a la conducta típica, antijurídica y, además, culpable (o en términos de las tesis bipartitas al injusto culpable) y no al tipo de injusto no culpable.

84 RoxIn, Claus. Política criminal y estructura del delito. Barcelona: PPU, 1992.

85 Vives Antón, Tomás. Fundamentos del sistema penal. Valencia: Tirant lo Blanch, 1996.

86 Roxin, Carlos. Derecho penal económico y de la empresa. Valencia: Tirant lo Blanch, 2007, p. 60.

87 lbíd., p. 31.

APROXIMACIONES

A UNA

FUNCIONALIZACIÓN

CONSTITUCIONAL

DE LA TEORÍA DEL

DELITO

APPROACHES TO A CONSTITUTIONAL

FUNCTION ON

THEORY OF CRIME 
el marco axiológico que se produce a partir de un acuerdo normativo fundamental (ética discursiva) alcanzado procedimentalmente por los sujetos participantes en una comunicación ideal.

Pero lo más interesante de la propuesta del profesor Vives Antón es el reordenamiento de los contenidos sistemáticos a partir de las exigencias de la norma penal, es decir, a partir de las diversas pretensiones de validez de la norma jurídico-penal. En la práctica, la diferencia fundamental de la propuesta de Vives con respecto a la de Roxin es la descarga de contenidos que se asumen en el nivel de la tipicidad y que en buena cuenta vienen confundiendo al operador jurídico. Nos referimos a la confluencia de tipicidad objetiva y tipicidad subjetiva en el mismo análisis de la tipicidad. Con ello, Vives Antón nos manifiesta que no existe una estructura objetiva ${ }^{88}$ en la teoría del delito que deba necesariamente respetarse. Un suceso criminal puede ser estudiado por una teoría del delito de contenidos diferentes. Su opción por una ordenación determinada de contenidos (sistemática) responde a su perspectiva de ser coherente con las diferentes pretensiones de validez que reconoce en una norma jurídica ${ }^{89}$. La norma jurídica penal, en la concepción de Vives, es portadora de una serie de valores garantistas, dada su unidad con el ordenamiento constitucional vigente ${ }^{90}$. En ese sentido, reconoce tres pretensiones de valide $z^{91}$ en la estructura de la teoría del delito y ello determina contenidos precisos en cada una de ellas.

- La tipicidad o antijuridicidad material: se orienta por la pretensión de relevancia tanto de la conducta realizada (desvalor de acción) como del resultado jurídico producido (desvalor de resultado). De acuerdo con esta concepción, únicamente son relevantes para el derecho penal los comportamientos riesgosos que amenacen o lesionen bienes jurídicos. No es parte de esta pretensión de relevancia la intención o el lado subjetivo del comportamiento.

- La antijuridicidad formal: se orienta por la pretensión de ilicitud y se compone de dos elementos de análisis. En primer lugar, se examina si el comportamiento concreto considerado relevante (tipicidad) contraviene la norma jurídica, entendida en su dimensión imperativa o directiva de conducta. En otras palabras, interesa en este aspecto saber si la intención que regía la realización de una conducta contraviene una prohibición o un mandato expresado en la norma. Ello no presupone ni la capacidad de autodeterminación del sujeto que realiza la acción ni el conocimiento efectivo de este de la prohibición de su

88 Vives Antón, Tomás. Fundamentos del sistema penal. Ob. cit., p. 483.

89 lbíd., pp. 484 y ss.

90 Martínez Bujan PÉRez, Carlos. Derecho penal económico y de la empresa. Ob. cit., p. 63.

91 No estamos considerando la pretensión de necesidad de penal propuesta por Vives Antón, dado el carácter contingente que supone dentro de la teoría del delito. 
conducta. En buena cuenta, lo que se analiza en primer lugar en la antijuridicidad formal es la existencia de dolo o imprudencia en el comportamiento de un sujeto.

Pero en este nivel de análisis interesa saber si el comportamiento relevante e intencionalmente dirigido a la realización de lo prohibido por la norma se encuentra bajo la cobertura de una norma de permisión (causas de justificación).

- La culpabilidad: se orienta por la pretensión de reproche, basada en la libertad de acción. En este punto el postulado de Vives Antón no discrepa en esencia de los postulados dominantes sobre la culpabilidad.

\section{III.3. Reconstrucción de una funcionalización constitu- cional de las categorías de la teoría del delito}

Retomando lo planteado por Roxin, pero teniendo en cuenta los cuestionamientos de su discípulo Amelung y los aportes de Vives Antón, corresponde ahora intentar reconstruir y evidenciar las bases constitucionales que dan fundamento vinculante y valorativo a los criterios más importantes que integran cada uno de los niveles de la teoría del delito. No pretendemos, ni mucho menos, abarcar todos o la mayoría de los criterios dogmáticos utilizados en la teoría del delito, sino solo aquellos que consideramos más relevantes. Estos criterios son herramientas importantes que permiten al operador judicial, finalmente, determinar racionalmente la relevancia penalmente típica de una conducta, su contrariedad a derecho, así como la reprochabilidad de la misma a una persona. Sigamos, a efectos de este trabajo, la sistemática tradicional de la concepción tripartita del delito.

\section{III.3.1. Tipicidad (antijuridicidad material)}

En este primer nivel de la teoría del delito, tal como ya lo indicaba Amelung, el principio de legalidad (garantía de taxatividad o mandato de determinación) viene a informar solo el límite formal (dúctil y graduable, por cierto) ${ }^{92}$ dentro del cual deben desarrollarse criterios materiales que ayuden a racionalizar el sentido del tipo penal, de cara a evaluar la relevancia típicamente penal de una concreta conducta. Tempranamente Amelung ${ }^{93}$ se dio cuenta de la función limitadamente formal $^{94}$ del principio de legalidad planteado por Roxin y advierte de

92 No olvidemos que ahora el canon del principio de legalidad no viene determinado en realidad por el tenor literal de la ley sino por los criterios de previsibilidad semántica, previsibilidad lógica o sistemática y previsibilidad axiológica.

93 AMELUNG, Knut. "Contribución a la crítica del sistema jurídico penal de orientación político-criminal de Roxin". En Bernd Schunemann (coord.). El sistema moderno del derecho penal: cuestiones fundamentales. Madrid: Tecnos, 1991, pp. 96 y 97.

94 Moccla, Sergio. El derecho penal: entre ser y valor. Función de la pena y sistemática teleológica. Montevideo: Editorial B de F, 2003, pp. 21-22 y 123 y ss., encuentra un rol material en la finalidad

APROXIMACIONES A UNA

FUNCIONALIZACIÓN CONSTITUCIONAL DE LA TEORÍA DEL DELITO

APPROACHES TO A CONSTITUTIONAL FUNCTION ON THEORY OF CRIME 
la necesidad de complementarlo con un principio que ofrezca una orientación material. En esa perspectiva, el referido autor reconoce que los tipos penales se encuentran vinculados al fin de protección de bienes jurídicos ${ }^{95}$, señalando incluso que esta función político-criminal del tipo penal «se define cada vez más con ayuda de consideraciones constitucionales» ${ }^{96}$. Este criterio marcará formas de delimitación del alcance del tipo penal a través de la interpretación teleológica. Esta finalidad o función de la tipicidad coincide con la función postulada por Vives en tanto pretensión de relevancia penal de una conducta.

Nosotros consideramos que existen varios principios que se deducen directa o implícitamente de disposiciones constitucionales y que inciden en el ámbito de la tipicidad. Estas disposiciones ofrecen una base constitucional vinculante a diversos criterios dogmáticos que modernamente se utilizan para acotar el sentido del tipo penal, es decir, para darnos criterios que nos permitan afirmar la relevancia penal de una conducta.

En primer lugar, siguiendo a Amelung y recientemente al propio Roxin, debe destacarse la orientación de la tipicidad al principio de protección subsidiaria y fragmentaria de bienes jurídicos ${ }^{97}$. De acuerdo con este principio, se protegen bienes jurídicos no frente a cualquier comportamiento causal o incluso previsible, sino a comportamientos que supongan la creación de riesgos prohibidos para bienes jurídicos. Este criterio fundamenta uno de los criterios más importantes de exclusión de imputación objetiva ${ }^{98}$ : el criterio del riesgo permitido. No puede ignorarse que la determinación del riesgo permitido viene marcada por una ponderación general, esencialmente previa al derecho penal, de intereses constitucionales concurrentes: «libertad vs. seguridad». Esta postura es compartida también por Sergio Moccia ${ }^{99}$ y el profesor Wolfgang Frisch ${ }^{100}$. Este último también hace referencia a las exigencias constitucionales de idoneidad, necesidad y adecuación para impedir determinadas lesiones contra bienes.

orientada al principio de legalidad o de determinación, cual es la protección de la libertad. Además, complementa esta finalidad con otra que está presente no solo en la tipicidad sino también en la antijuridicidad. Nos referimos a la finalidad de la pena como integración social. Un tipo penal suficientemente preciso y comprensible, señala Moccia, contribuye a la integración social. 95 lbíd.

96 Amelung, Knut. Ob. cit., p. 97.

97 Roxin, Claus. Evolución y modernas tendencias de la teoría del delito en Alemania. México D.F.: UBJUS, 2008, pp. 21 y 22. Este autor recientemente ha reparado en el criterio excesivamente formal de hacer descansar la tipicidad en la finalidad prescrita por el principio de legalidad. En la actualidad, siguiendo a su discípulo, hace descansar la finalidad de la tipicidad en la protección subsidiaria de bienes jurídicos.

98 lbíd., pp. 23 y ss.

99 MoccIA, Sergio. Ob. cit., p. 142.

$100 \mathrm{FRISCH}$, Wolfang. "La teoría de la imputación objetiva del resultado: lo fascinante, lo acertado y lo problemático». En Wolfgang FRISCH y Robles PLANAS (auts.). Desvalorar e imputar. Barcelona: Atelier, 2004, p. 42. 
El principio de protección subsidiaria de bienes jurídicos se encuentra fundamentado en la fórmula de Estado social y democrático de derecho que reconoce nuestra Constitución (artículos 44 y 45 de la Constitución peruana) y en el principio de proporcionalidad que es su expresión concreta (artículo 200 de la Constitución). Este reconocimiento constitucional ha sido recogido por nuestro Tribunal Constitucional en la sentencia de fecha 15 de diciembre de 2006 (ver fundamentos 9 y 27).

En segundo lugar, otro principio que ha devenido esencial para la delimitación del tipo penal es el principio de responsabilidad por el hecho propio. Sobre la base de este principio se han desarrollado los modernos criterios de exclusión de imputación objetiva que conocemos hoy como prohibición de regreso, principio de confianza y ámbito de responsabilidad de la víctima ${ }^{101}$. Este principio prescribe tres tipos de relaciones para poder atribuir un hecho a una persona y hacerla responsable por ello. En palabras de Cuerda Riezu, «se impone una pena a alguien porque ha habido una previa declaración de responsabilidad penal (tercera relación), y se ha efectuado esa declaración porque precisamente ese alguien, y no otra persona, es la que ha cometido un delito (primera relación) y, por lo tanto, se le hace responsable del mismo (segunda relación)». La vulneración del principio se produce con la infracción a cualquier tipo de relación que la compone.

Interesa, para efectos de nuestro tema, la segunda relación descrita. Efectivamente, como paso previo a la declaración de responsabilidad penal de una persona o determinadas personas ${ }^{102}$ (culpabilidad), el principio exige la atribución, como propia, de la conducta de una personas (o de varias personas) a un tipo penal determinado y, por lo tanto, no a la conducta de otra u otras personas ${ }^{103}$.

Una consecuencia importante de esta dimensión del principio de responsabilidad personal por el hecho propio lo constituye la dimensión negativa o excluyente que se deduce de tal principio ${ }^{104}$. Esta expresión

101 Una mirada de estos criterios de exclusión de imputación objetiva sobre la base del principio de responsabilidad por el hecho propio puede verse en ROBLES PLANAS, Ricardo. La participación en el delito: fundamento y límites. Madrid, 2003, y MARAVER GÓMEZ, Mario. El principio de confianza en derecho penal. Madrid: Civitas-Thomson Reuters, 2009.

102 Señala CUERDA RIEZU, Antonio. «El principio constitucional de responsabilidad personal por el hecho propio. Manifestaciones cuantitativas». Madrid: ADPCP, LXII (2009), p. 222, que «el principio de responsabilidad por el hecho propio no exige que el responsable de un hecho sea único, sino que sus responsables del mismo, sean estos cuantos sean, tengan una relación de pertenencia respecto al hecho, en el sentido de que se les puede atribuir el hecho como propio».

103 Luzón PEÑA, Diego Manuel. Lecciones de derecho penal. Parte general. Valencia: Tirant lo Blanch, 2012, p. 31, señala que «normalmente se vincula este principio a los de culpabilidad y responsabilidad subjetiva, pero realmente significa ya la exigencia de un injusto típico, de realización personal o colaboración personal en un tipo de injusto».

104 Según MARAVER GÓmeZ, Mario. Ob. cit., p. 238, el principio de responsabilidad personal por el hecho propio (el autor lo denomina principio de autorresponsabilidad) contiene dos caras de una misma moneda: «por un lado se entiende de que un sujeto solo debe responder por lo que él mismo ha realizado (dimensión positiva), y por otro lado, se entiende que el sujeto no debe responder por lo que un tercero ha realizado (dimensión negativa).

APROXIMACIONES

A UNA

FUNCIONALIZACIÓN

CONSTITUCIONAL

DE LA TEORÍA DEL DELITO

APPROACHES TO A CONSTITUTIONAL FUNCTION ON THEORY OF CRIME 
negativa del principio fundamentaría, entonces, los criterios de exclusión de imputación objetiva que hemos mencionado:

- Prohibición de regreso: si alguien o varios ya son atribuidos como autores de un delito (les pertenece), entonces no puede ser de otro o de otros sujetos. Se excluye la relación de autoría, pudiéndose atribuir solamente una responsabilidad como partícipe.

- Principio de confianza: a nadie puede atribuírsele la infracción del deber de cuidado que alcanza a otro. Más allá de que a una persona le competa la custodia o control de determinadas fuentes de peligro, no le corresponde un ilimitado deber de cuidado sobre aquellas $^{105}$. En otras palabras, lo que corresponde exclusivamente como deber de cuidado de una persona no tiene por qué ser atribuido a otra persona.

- Ámbito de responsabilidad de la propia víctima: a nadie puede atribuírsele algo que le compete esencialmente al propio titular del bien jurídico afectado.

Dado que el principio de responsabilidad personal por el hecho propio no tiene un reconocimiento positivo expreso, no ha resultado hasta ahora claro el tipo de fundamento constitucional que sustenta este principio. El Tribunal Constitucional español ha mantenido dos tendencias jurisprudenciales al respecto ${ }^{106}$ : por un lado, ha fundamentado el referido principio sobre la base del principio de legalidad (artículo 25.1 de la Constitución) ${ }^{107}$, y por otro, ha fundamentado el mismo principio sobre la base del principio de culpabilidad.

Nuestro Tribunal Constitucional solo ha reconocido las garantías tradicionales del principiode culpabilidad: prohibición de responsabilidad objetiva, principio de reprochabilidad (con las diversas dimensiones de exigibilidad que ello supone) y la exigencia de proporcionalidad al momento de la individualización de la pena al culpable ${ }^{108}$. Sin embargo, en la sentencia de fecha 14 de diciembre de 2005 (expediente 86052005 AA/TC), el Tribunal Constitucional se refirió al principio de prohibición de responsabilidad por hechos de terceros en un asunto relacionado con el derecho administrativo sancionador. No obstante, si bien el Tribunal no niega el reconocimiento del referido derecho (el mismo que es alegado por los demandantes sobre la base del principio

105 Desde una perspectiva estrictamente normativa (no necesariamente valorativa) MARAVER GómEZ, Mario. Ob. cit., p. 274, señala que el principio de responsabilidad sirve como principio destinado a delimitar el ámbito de responsabilidad en dos momentos diferentes, dando lugar a dos criterios de imputación o valoración igualmente diferentes: por una parte la prohibición de regreso y, por otra parte, el principio de confianza", siendo la principal diferencia el hecho que "este último presupone que el sujeto ostente una posición de garante».

106 CUERDA RIEZU, Antonio. Ob. cit., pp. 181-183, describe el desarrollo jurisprudencial al respecto.

107 Esta es la posición que recoge LUZÓN PEÑA, Diego Manuel. Ob. cit., p. 31.

108 STC de fecha 9 de agosto de 2006 (expediente 003-2005 PI/TC) y STC de fecha 19 de enero de 2007 (expediente 00014-2006 AI-TC). 
de legalidad y debido proceso), le retira de forma preocupante toda virtualidad práctica. Según el Tribunal, la invocación del principio de prohibición de responsabilidad por el hecho de terceros obligaría al Tribunal a hacer un análisis del material probatorio utilizado, aspecto que ya no es de su competencia constitucional.

Roxin y la doctrina funcional dominante incluyen, en el ámbito de la tipicidad, las exigencias del mandato de determinación, es decir, la dimensión imperativa de la norma penal. Es en ese sentido que exigen la concurrencia de una dimensión subjetiva del hecho típico, es decir, la exigencia de dolo o culpa (si corresponde) en la realización del hecho típico. Luego de un largo proceso de maduración, nosotros coincidimos con Vives Antón en el sentido de que se trata de un elemento (el subjetivo) que corresponde a una pretensión de validez de la norma, y en ese sentido, el elemento subjetivo no es un elemento de análisis en el ámbito de la tipicidad entendida como antijuridicidad material, sino de la antijuridicidad formal.

\section{III.3.2. La antijuridicidad formal}

Siguiendo en parte la perspectiva de Vives Antón, esta categoría de la teoría del delito se relaciona con la pretensión de ilicitud de la norma jurídico-penal y, en ese sentido, con dos elementos de análisis: (i) la exigencia de un comportamiento dirigido a la realización de la vulneración de lo prohibido o mandado por la norma penal ${ }^{109}$, y (ii) la evaluación de una norma de permisión en el ordenamiento jurídico. El primero se relaciona con el principio de taxatividad o mandato de determinación (norma en sentido imperativo), pero también con la prohibición de responsabilidad objetiva (principio de culpabilidad). Se trata en buena cuenta de la exigencia de imputación subjetiva (dolo o culpa cuando corresponda) que determine un verdadero acto contrario a la norma en sentido imperativo. El segundo elemento de análisis se vincula con el principio de proporcionalidad en sentido estricto, dado que se trata de un ámbito de relación conflictiva de principios e intereses concurrentes en un suceso real.

Este segundo nivel de análisis se relaciona con lo que la doctrina dominante reconoce como simplemente antijuridicidad y su correlato de análisis negativo a través de las causas de justificación. Roxin asignaba a este ámbito de la teoría estándar del delito la función de solución de conflictos. Sin embargo, como habíamos mencionado, Amelung ${ }^{110}$

109 Un aspecto esencial de las posturas de MARTínez-BuJÁn PÉreZ, Carlos. Ob. cit., pp. 53 y ss. y de MOLINA FERNÁNDEZ, Fernando. Antijuridicidad penal y sistema de delito. Bogotá: Bosch/Universidad, 2010, pp. 515 y ss, es que, a este nivel de la antijuridicidad formal vinculada con la dimensión imperativa de la norma jurídica, resultan esenciales los aspectos que en parte hacen operativa a la norma, esto es, aquellos elementos relacionados con la capacidad de motivar en "contra de la realización del delito".

110 AmELUNG, Knut. Ob. cit., p. 95.

APROXIMACIONES A UNA

FUNCIONALIZACIÓN CONSTITUCIONAL DE LA TEORÍA DEL DELITO

APPROACHES TO A CONSTITUTIONAL FUNCTION ON THEORY OF CRIME 
cuestiona el rendimiento de esta función, indicando que con la propuesta de espacio de solución de conflictos no se está asignando una función específica, dado que el derecho, en términos generales, es un espacio de solución de conflictos.

En ese sentido, siguiendo la terminología de Martínez Buján Pérez ${ }^{111}$, la función esencial de este ámbito de la antijuridicidad formal radica en el análisis de si la conducta considerada ofensiva para bienes jurídicos constituye, en el conjunto del ordenamiento jurídico, un comportamiento que infringe la norma jurídica (realiza lo prohibido o no realiza lo mandado). Ello supone la evaluación de la posibilidad de permisos que determinen la exclusión de la ilicitud de un comportamiento considerado ofensivo o relevante. Sin embargo, a diferencia de lo que considera Martínez Bujan, nosotros consideramos que estos permisos presuponen supuestos de conflictos de derechos o principios sobre los cuales el legislador ha establecido reglas o criterios (más o menos detallados) para su ponderación adecuada. La crítica vertida a esta postura ponderativa que subyace a las causas de exclusión de la ilicitud se debía a las posturas que no encontraban un criterio único que fundamentara de manera general los supuestos de causas de exclusión de la ilicitud o causas de justificación generalmente aceptados.

El texto de Fernando Molina ${ }^{112}$ es muy esclarecedor al respecto. Las causas de justificación, a pesar de la discrepancia de un sector de la doctrina que afirma la pluralidad de fundamentos de las causas de justificación, contienen un fundamento último ulterior que las informa. Molina argumenta de manera fundada que todas las causas de justificación (salvo el consentimiento en su dimensión de acuerdo) tienen un contexto común y puede postularse un principio fundamental único. El contexto común es la situación de conflicto de intereses que genera la acción. Esta, por un lado, lesiona materialmente (o pone en peligro) bienes jurídicos, y por otro, salva otros bienes. El segundo paso es saber si existe un criterio común general a todas las causas de justificación para enfrentar su resolución. El mencionado autor postula que es la ponderación del interés preponderante. Replicando a aquellos que se oponen a la posibilidad de un fundamento único (interés preponderante), señala que estos cuestionan una interpretación tosca o simplista del referido principio de ponderación ${ }^{113}$. Señala el autor que incluso la legítima defensa se sitúa en el contexto de una ponderación de intereses ${ }^{114}$. Solo es necesario todo el contexto valorativo que está

111 Martínez-Buján Pérez, Carlos. El contenido de la antijuridicidad. Valencia: Tirant lo Blanch, 2013, pp. 53 y 72 .

112 Molina Fernández, Fernando. Estado de necesidad y justificación penal. Bogotá: Universidad Santo Tomás/lbáñez, 2009.

113 lbíd., p. 27, indica que es simplista porque lo único decisivo para dicha forma de ponderar es la comparación del valor absoluto de los bienes inmediatos.

114 lbíd., p. 33. 
en juego en una situación de legítima defensa. Compartimos entonces la conclusión del profesor Molina cuando señala que:

[...] la teoría del interés preponderante, como expresión última de toda causa de justificación, se limita a decir algo tan neutro y a la vez tan obvio como que los conflictos de intereses en el seno del sistema jurídico deben resolverse a favor de los intereses preponderantes conforme a las valoraciones de dicho sistema jurídico, pero no pone límites a lo que pueda ponderarse.

Esta perspectiva nos lleva claramente al subprincipio de proporcionalidad en estricto o balancing ${ }^{115}$. Este subprincipio es uno de los criterios del test de proporcionalidad, y en el Perú, el Tribunal Constitucional lo ha deducido tanto de la fórmula que reconoce a nuestro Estado como un Estado social y democrático de derecho como del artículo 200 de la Constitución política. En efecto, en sentencias de fecha 9 de agosto de 2006 (expediente 003-2005 AI), y especialmente de fecha 15 de diciembre de 2006 (expediente 0012-2006 PI-TC), entre otras múltiples sentencias, el Tribunal Constitucional ha reconocido la constitucionalidad del principio de proporcionalidad y, dentro de él, del subprincipio de proporcionalidad en estricto.

Sin embargo, debe señalarse que, a diferencia de la ponderación de intereses que se contienen en el tipo penal y que obedecerían a una configuración previa (legislador), aquí el juez hace una verdadera valoración de la ponderación de los derechos o principios en juego, aunque de manera reglada por los requisitos que el legislador ha colocado en cada una de las causas de justificación en específico.

\section{III.3.3. Culpabilidad}

La amplia mayoría de perspectivas coinciden en que en este nivel de la teoría del delito lo esencial es satisfacer la pretensión de reproche de la norma penal, y ello pasa por la tradicional discusión sobre la libertad humana como fundamento del reproche.

Si bien los hallazgos del neurocientífico Benjamin Libet en el año 1982 han acentuado el debate sobre la inexistencia de libertad y de la capacidad de autodeterminación del ser humano, sus conclusiones ${ }^{116}$ no han sido interpretadas de manera uniforme. Según una determinada interpretación, estos hallazgos probarían que el ser humano no actúa

115 Ampliamente sobre este subprincipio ALEXY, Robert. Teoría de la argumentación jurídica. Madrid: Centro de Estudios Constitucionales, 1989; BERNAL PULIDO, Carlos. El principio de proporcionalidad y derechos fundamentales. Madrid, 2003, pp. 77 y ss.; LOPERA MESA, Gloria Patricia. Principio de proporcionalidad y la ley penal. Madrid: Centro de Estudios Políticos y Constitucionales, 2006, pp. 497 y ss.

116 Delgado García, José M. «Decidir no es cosa de dos». Un ensayo sobre la neurofisiología de la toma de decisiones». Revista de Occidente (Libertad y cerebro), enero (2011), p. 23.

APROXIMACIONES

A UNA

FUNCIONALIZACIÓN

CONSTITUCIONAL

DE LA TEORÍA DEL

DELITO

APPROACHES TO A CONSTITUTIONAL

FUNCTION ON

THEORY OF CRIME 
de forma libre y autónoma ${ }^{117}$. Sin embargo, otros científicos niegan que de tales hallazgos pueda deducirse tan graves conclusiones con relación a la libertad humana. Estos científicos afirman que tales experimentos son simplistas y están basados en operaciones sencillas y elementales que no caracterizan la gran gama de delitos posibles y complejos de cometer ${ }^{118}$. Se afirma también que del descubrimiento de explicaciones causales en la toma de decisión no puede deducirse la negación de la libertad.

El concepto de libre albedrío ya había sido cuestionado un poco antes de los hallazgos de Libet y, por tal motivo, se había emprendido una serie de esfuerzos por reconstruir el concepto de libertad que sustenta el juicio de culpabilidad y que permitiera eludir la indemostrabilidad del libre albedrío y el aparente determinismo detectado por las neurociencias. En ese proceso reconstructivo se han planteado teorías como la denominada «teoría social de la culpabilidad» ${ }^{119}$, o teorías que, si bien aceptan que no se puede demostrar la libertad concreta del procesado en el hecho concreto, sí puede afirmarse una libertad general como «accesibilidad a la norma», «expresión de la personalidad del autor» o «disposición jurídica mínima» como sustitutos del «poder actuar de otro modo» ${ }^{120}$.

Como puede evidenciarse, hasta el momento no existe acuerdo o seguridad sobre las bases deterministas del ser humano, aunque tampoco de sus bases indeterministas. Bajo estas bases inseguras, el profesor Frisch sostiene que los juristas trabajan con decisiones basadas en criterios normativos y valorativos (juzgadas sobre bases de interacción comunicativa basadas en el discurso) ${ }^{121}$. Es decir, las personas se tienen a sí mismas como razonables y actúan adscribiendo dicha razón también a quienes participan en el discurso ideal sobre el derecho. Estas personas se tienen a sí mismas y a los participantes en el discurso como razonables y capaces de desarrollar un comportamiento acorde con la pauta de la norma. Se aprecia, entonces, una autoconvicción social de la libertad

117 Podría mencionarse en esta posición el manifiesto de un grupo de científicos alemanes en el año 2002 (Das Manifest, Elf fhrende Neurowissenschaftler über Gegenwart und Zukunft der Hirnforschung).

118 Sobre los representantes de esta otra interpretación de los hallazgos de Libet puede verse FRISCH, Wolfang. "Sobre el futuro del derecho penal de la culpabilidad». En Derecho penal de la culpabilidad y neurociencias. Madrid: Civitas /Thomson Reuters, 2012, pp. 30-32.

119 Planteado claramente por JESCHECK, Hans H. en 1981, según lo cual no se analiza la libertad de actuar de otro modo de una concreta persona en la situación concreta imputada, sino sobre la base de un hombre ideal colocado en la situación de la citada persona. Esta posición ha sido cuestionada posteriormente por SCHUNEMANN, Bernd. "La culpabilidad: estado de la cuestión". En Roxin, C., G., JaKobS, B. SCHÜnemanN, W. FRISCH y M. KöHLER. Sobre el estado de la teoría del delito. Madrid: Civitas, 2000, pp. 105 y 106.

120 Tampoco pueden dejarse de lado las posiciones como las del profesor SCHUNEMANN, Bernd. «La culpabilidad: estado de la cuestión». En Sobre el estado de la teoría del delito. Madrid: Civitas, p. 2000, p. 109, que plantea una perspectiva asentada sobre bases del interaccionismo simbólico (estructura del lenguaje humano) para fundamentar el libre albedrío humano.

121 FIRSCH, Wolfgang. "Sobre el futuro del derecho penal de la culpabilidad». En Derecho penal de la culpabilidad y neurociencias. Madrid: Civitas/ Thomson Reuters, 2012, pp. 63-65. 
de decisión de los humanos, salvo excepcionales condicionamientos anormales ${ }^{122}$.

Pues bien, nuestra Constitución política, como prácticamente casi todas las actualmente vigentes en el mundo occidental, parte de esta visión autocomprensiva de la capacidad de decisión libre de los humanos ${ }^{123}$, y esto se evidencia sobre todo en el abrumador dato sociológico de las percepciones, convicciones y necesidades sociales. En un modelo de Estado como el nuestro, el reproche por una conducta típicamente injusta solo puede fundarse en esta autopercepción recíproca de que el ser humano puede comportarse de acuerdo con la pauta de una norma penal democráticamente concebida.

En consecuencia, y teniendo en cuenta esta perspectiva constitucional, la categoría de la culpabilidad como nivel de la teoría del delito (que exige un juicio de reproche para imponer una pena a una persona por una conducta típicamente injusta) es una manifestación del principio de culpabilidad ${ }^{124}$. Este principio tiene como función esencial determinar un límite infranqueable a la maximización punitiva que plantean los fines preventivos de la pena y el derecho penal ${ }^{125}$.

El principio de culpabilidad se deriva, en nuestro concepto, de diversas disposiciones constitucionales que recogen explícitamente el principio de dignidad de la persona ${ }^{126}$, así como el principio o derecho a la libertad, en tanto perspectiva que recoge esa visión autocomprensiva del ser humano como un ser libre.

A pesar de estas consideraciones de la doctrina, que compartimos, las sentencias de nuestro Tribunal Constitucional de fecha 9 de agosto de 2006 (expediente 0003-2005 AI TC) y de 19 de enero de 2007 (expediente 0014-2006 AI-TC) deducen el referido principio curiosamente en el principio de legalidad $2.24 \mathrm{~d}$ (especialmente mandato de determinación y lex previa) y en el de proporcionalidad (artículo 200 de la Constitución).

122 LUZÓn PeÑA, Diego Manuel. Lecciones de derecho penal. Parte general. Valencia: Tirant lo Blanch, 2012, p. 503.

123 Ibíd., p. 504.

124 El principio de culpabilidad es un mandato de optimización cuyo alcance desborda el ámbito del último nivel dogmático de la teoría del delito. El principio de culpabilidad, entre sus principales exigencias o garantías, demanda (i) la prohibición de la responsabilidad objetiva; (ii) la exigencia de reprochabilidad (aquí nos situamos en la culpabilidad como nivel de la teoría del delito), y (iii) la responsabilidad personal por el hecho propio, del cual hemos dado cuenta en el ámbito de la tipicidad. Sobre el amplio alcance del principio de culpabilidad puede consultarse MIR PUIG, Santiago. Bases constitucionales del derecho penal. Madrid: lustel, 2011, pp. 126 y ss.; JAÉN VALLEJO, Manuel. Principios constitucionales y derecho penal moderno. Buenos Aires: Ad Hoc, 1999, pp. 39 y ss.; y RUSCONI, Maximiliano y Mariano KIERSZENBAUM. Teoría del delito y garantías constitucionales. Buenos Aires, 2009, pp. 97 y ss.

125 Sobre esta función FRISCH, Wolfang. Ob. cit., pp. 55 y ss. y MOR PUIG, Santiago. Bases constitucionales del derecho penal. Madrid: lustel, Madrid, 2011, p. 133.

126 Sobre este fundamento, MIR PUIG, Santiago. Bases constitucionales del derecho penal. Ob. cit., p. 125 y 126.

APROXIMACIONES A UNA

FUNCIONALIZACIÓN

CONSTITUCIONAL

DE LA TEORÍA DEL

DELITO

APPROACHES TO A CONSTITUTIONAL

FUNCTION ON

THEORY OF CRIME 


\section{CONCLUSIONES}

El proceso de constitucionalización del derecho penal ha motivado que los tradicionales principios político-criminales que limitan la potestad punitiva del Estado (legalidad, proporcionalidad, lesividad, culpabilidad) se constituyan ahora en principios normativos y vinculantes. Sin embargo, este fenómeno solo ha operado con relación al legislador penal, esto es, para los procesos de criminalización. Nosotros creemos que el referido proceso de constitucionalización - $-\mathrm{y}$, en específico, la concepción neoconstitucionalista del derecho- tiene un impacto sobre la dogmática penal y, en virtud de ello, sobre el contenido de los diferentes niveles de la teoría del delito.

Efectivamente, el neoconstitucionalismo plantea, a diferencia del positivismoclásico, una relación necesaria (al menos en planoconceptual) entre el derecho y la moral, entendiendo por esta última no una moral positiva o particular, sino una moral crítica generada a partir del discurso comunicativo de los participantes en una sociedad democrática. En la actualidad, esta moral crítica se encuentra concretizada de mejor manera en la dimensión axiológica que se incorpora en los principios y derechos fundamentales contenidos en las constituciones de los países democráticos. Estas normas iusfundamentales operan como pretensiones de corrección (la norma que debe ser) de las normas en su dimensión descriptiva (la norma que es).

Esta perspectiva del derecho nos lleva a entender que la norma jurídica iusfundamental, y también las normas jurídico-penales, están compuestas de dos dimensiones: por un lado una dimensión imperativa o prescriptiva, y por otro, una dimensión axiológica o moral (pretensiones de corrección).

Concebido así el derecho, no puede definirse más el derecho penal solo como el conjunto de normas jurídicas entendidas como reglas a las cuales se adscriben consecuencias penales, sino como conjunto de normas, reglas, principios y valores a los cuales se adscriben consecuencias penales. Además, la inclusión de una dimensión axiológica en la norma penal determina aceptar metodológicamente operaciones de carácter ponderativo (entre principios y derechos fundamentales) antes de delimitar el alcance del tipo penal. Ambas consideraciones constituyen presupuestos básicos para la construcción de una dogmática penal funcional.

Efectivamente, la dogmática penal, entendida tradicionalmente como aquella disciplina que tiene por objeto el conocimiento de las normas jurídico-penales y la ordenación de los distintos conceptos logrados en un sistema científico lógicamente coherente, no resulta ya suficiente en el contexto del neoconstitucionalismo. Esta concepción resultaba coherente con una concepción positivista clásica del derecho y, en 
tal sentido, limitadamente garantista. En efecto, bajo esta dimensión positivista legalista la dogmática penal podía ser formalmente útil tanto a una legislación penal democrática como autoritaria. Es decir, se trataría de una dogmática penal sin ninguna pretensión de corrección frente a las insuficiencias, lagunas axiológicas o defectos de la legislación penal.

La dogmática penal y la teoría del delito en el contexto del neoconstitucionalismo supone mantener una actitud crítica (o axiológica) frente a los enunciados legales, y esto solo puede producirse sobre la base de una funcionalización constitucional de los contenidos de la teoría del delito.

Una perspectiva neoconstitucional de la teoría del delito no supone necesariamente una estructura objetiva de los niveles tradicionalmente conocidos ni una exigencia inamovible de determinados contenidos en tales niveles. Sin embargo, en la construcción sistemática, no se puede prescindir de la fuerza vinculante de los principios y derechos fundamentales en el proceso de aplicación de las disposiciones penales ni tampoco de las dos dimensiones de la norma jurídico-penal (la imperativa y la axiológica). Estas determinan una teoría del delito marcada por pretensiones de validez: de relevancia en la tipicidad, de ilicitud en la antijuridicidad formal y de reproche en la culpabilidad. Los principios o derechos fundamentales que coadyuvan a cumplir con dichas pretensiones tienen ahora carácter vinculante y deben tenerse en cuenta al momento de construir dogmática penal.

Así, la pretensión de relevancia se resguarda con un análisis del comportamiento desde los principios de protección subsidiaria y fragmentaria del bien jurídico, así como desde el principio de responsabilidad por el hecho propio. Estos principios se materializan en diferentes criterios de exclusión de imputación objetiva, como los criterios de riesgo permitido, prohibición de regreso, principio de confianza y ámbito de responsabilidad de la víctima.

Por otro lado, la pretensión de ilicitud se encuadra en criterios esbozados por el principio de determinación o taxatividad y por el principio de proporcionalidad en sentido estricto. Esto último en razón del contexto conflictivo que plantean las normas de permisión.

Finalmente, la categoría de la culpabilidad o ámbito de pretensión del reproche se fundamenta en el principio de autopercepción de la libertad humana y cumple la función de límite frente a la lógica expansiva de los criterios preventivos. 